\title{
Perda da marca de plural no português brasileiro: contribuições da Fonologia
}

\author{
Phonological traces in the loss of a plural marke in \\ Brazilian Portuguese
}

\author{
Thaïs Cristófaro Silva' \\ Universidade Federal de Minas Gerais \\ Leonardo Almeida \\ Universidade Federal de Minas Gerais \\ Christine Guedri \\ University of Texas at Austin
}

\begin{abstract}
A number of recent works has shown that linguistic representations incorporate redundant information which plays an important role in linguistic systems. Works on experimental phonetics and along the lines of Laboratory Phonology indicate the gradual nature of phonetic representations (BROWMAN; GOLDSTEIN, 1992; ZSIGA, 1995; ALBANO, 2001; BYBEE, 2001, 2002; PIERREHUMBERT, 2001). This paper follows this line of research by investigating plural loss in Brazilian Portuguese. We will investigate lenition in Brazilian Portuguese plural forms that end in a sibilant, as in mês 'month' whose plural form is meses 'months'. This paper offers evidence for the gradual implementation of phonetic changes by showing that the loss of a morphological category (plural) leaves traces in the continuum of speech in the form of compensatory lengthening.
\end{abstract}

Keywords

Phonology, Morphology, Phonetics, Plural forms 


\section{Resumo}

A literatura recente mostra que as representações lingüísticas incorporam informações redundantes as quais desempenham um papel importante nos sistemas lingüísticos. Trabalhos em fonética experimental, com foco em Fonologia de Laboratório, indicam a natureza gradual das representações fonéticas (BROWMAN; GOLDSTEIN, 1992; ZSIGA, 1995; ALBANO, 2001; BYBEE, 2001, 2002; PIERREHUMBERT, 2001). Este artigo segue esta última linha de pesquisa e investiga a perda de marca de plural no português brasileiro. Será investigada a lenição em formas de plural que terminam em uma sibilante, como em mês > meses. Este trabalho oferece evidência da implementação gradual de mudanças fonéticas ao mostrar que a perda de uma categoria morfológica (plural) deixa vestígios no continuum da fala através de alongamento compensatório.

\section{Palavras-chave}

Fonologia, Morfologia, Fonética, Formas de plural 


\title{
1. Introdução
}

\begin{abstract}
A natureza das representações mentais tem sido foco de intenso debate na lingüística atual. Os modelos derivacionais postulam representações categóricas que podem ser alteradas através da aplicação de regras específicas. A Teoria da Otimalidade (OT) sugere que a interação entre restrições seleciona a representação mais apropriada, ou forma ótima. Assim, tanto em modelos derivacionais quanto em modelos que formulam restrições, temos representações lingüísticas categóricas. Informações redundantes - por exemplo, aquelas referentes à alofonia ou sobre o detalhe fonético - não constam das representações linguísticas dos modelos derivacionais ou da OT. Contudo, um grande número de trabalhos recentes mostra que as representações lingüísticas incorporam informações redundantes e que tais informações desempenham um papel importante no processamento da linguagem. Diversos trabalhos experimentais, seguindo as linhas da Fonologia de Laboratório, indicam a natureza gradual das representações fonéticas (BROWMAN; GOLDSTEIN, 1992;ZSIGA, 1995;ALBANO 2001; BYBEE, 2001, 2002; PIERREHUMBERT, 2001; MOWREY; PAGLIUCA, 1995). Uma pergunta que surge com esses trabalhos diz respeito à natureza das representações lingüísticas: elas são categóricas ou gradientes? Este trabalho busca contribuir para a resposta dessa pergunta. Mais especificamente, pretende-se avaliar se a perda de uma categoria morfológica (plural) deixa vestígios no contínuo da fala. Na tentativa de aprofundar mais essa questão, avalia-se a perda da marcação de plural em substantivos e adjetivos que terminam em sibilante (ex. mês $>$ meses).
\end{abstract}

\subsection{Sobre a perda da marca de plural no português brasileiro}

Uma característica recorrente do português brasileiro (doravante PB) é a perda, opcional, da marca de plural em substantivos e adjetivos (SCHERRE, 1998; NARO; SCHERRE, 2003; GUY, 1981; GUY, 1989 e CRISTÓFAROSILVA et al, 2005). Assim, encontramos formas em competição quando em uma 
frase nominal a marca de plural ocorre em todos os constituintes, ou seja, no artigo, no substantivo e no adjetivo, ou a marca de plural é preservada somente no constituinte mais à esquerda da frase nominal: " "os meninos bonitos " e "os menino bonito", ou "uns dias alegres " e "uns dia alegre". Considere a tabela que segue.

A Tabela 1 apresenta casos de perda da marca de plural do PB. Em todos os exemplos em tal tabela, a terceira coluna apresenta a perda da marca de plural na forma nominal. ${ }^{3} \mathrm{O}$ artigo definido ou indefinido preserva a marca de plural que é omitida nos substantivos ou adjetivos. As cinco possibilidades de formação de plural nominal no PB estão listadas de a-f na Tabela 1 (CUNHA; CINTRA, 1985). Os casos em (a) representam a forma de plural regular que é o padrão mais freqüente da língua. Nesses casos, um simples morfema (-s) é adicionado ao final da forma nominal. As formas de plural nominal em (b) apresentam dois marcadores de plural distintos no mesmo substantivo ou adjetivo: morfema (-s) final e a mudança na qualidade da vogal tônica. Desse modo, a forma singular "r[o]sto" ocorre como "r[o]stos" no plural, ou seja, uma vogal média alta fechada no singular ocorre como uma vogal média baixa aberta em formas de plural e há também a presença do morfema de plural (-s). Os casos em (c) envolvem palavras cujas formas no singular terminam em /1/. Nesses casos, a consoante lateral possui forma vocalizada na maioria das variantes do PB: sa/l/ > sa[w] (QUEDNAU, 1994). Na formação do plural, ocorre o desaparecimento do segmento final da forma do singular (que pode ser tanto uma lateral quanto um glide posterior: sa[1] ou sa[w]) e a seqüência segmental [is] é adicionada à forma nominal: $\mathrm{sal}>\mathrm{sa}[\underline{i \mathbf{s}}] .{ }^{4}$ Já os casos em (d) ilustram palavras que terminam em róticos. Ocorre grande variedade de realização fonética entre eles dependendo, sobretudo, da variedade dialetal no PB (CRISTÓFARO-SILVA, 2002). Na variedade considerada neste artigo, o português brasileiro falado na cidade de Belo Horizonte, os róticos em fim de sílaba são pronunciados como fricativas, sejam elas velares ou glotais. A palavra "flor", por exemplo, é pronunciada como [ ' $\mathrm{floh}$ ] ou [ ' $\mathrm{floX}$ ]. Nas formas de plural, o R-final é pronunciado como um tepe e o sufixo [is] é adicionado: [ $\mathrm{floh}]>$ [ ' floris ]. Os casos em (e) representam formas nominais de plural de nomes terminados em (ão). Esses casos podem apresentar três terminações de plural: ãos, ães, ões. Exemplos são: "mão" > "mãas", "capitão" > "capitães" e "leão" > "leõos". Finalmente, os casos em (f) ilustram nomes terminados em (-s) os quais recebem como marca de plural (-is): mês $>$ mes[is] . O presente artigo investiga a perda de marca de plural nos casos apresentados em (f) ${ }^{5}$ 
TABELA 1

Casos de perda de marca de plural

\begin{tabular}{|c|c|c|}
\hline Tipo de Marcador de Plural & Singular & Plural > Perda da marca de plural \\
\hline (a) s plural ${ }^{6}$ & "o menino" & "os menino $\underline{s} ">$ "os menino" \\
\hline (b) metafonia & "um r[o]sto" & "uns $\mathrm{r}[$ ○ ] stos" > "uns r r[o]sto" \\
\hline (c) 1 em final de palavra & "o sal" & 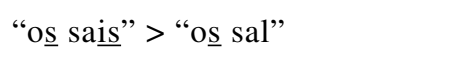 \\
\hline (d) $r$ em final de palavra & "a flor" & "as flores" $>$ "as flor" \\
\hline (e) ão final: $\tilde{A} O>$ ões, ãos, ães & "um leão" & "uns leões" > "uns leão" \\
\hline (f) s em final de palavra & "o mês" & "os meses" > "os mês" \\
\hline
\end{tabular}

Um grande número de trabalhos aborda a perda da marca de plural em diferentes variedades do BP de um ponto de vista morfológico e sintático. Entre os trabalhos que discutem esse tema destacam-se Scherre (1998); Naro e Scherre (2003); Guy (1981) e Guy (1989). Contudo, pouco se disse a respeito das consequiências fonológicas relacionadas com a perda de marca de plural. Este trabalho pretende contribuir para o preenchimento dessa lacuna ao avaliar se a perda de uma categoria morfológica (plural) deixa vestígios no contínuo da fala. Demonstra-se que, quando ocorre a perda da marca de plural em formas nominais terminadas em sibilantes (ex. mês > meses), observa-se maior duração segmental do que a duração tipicamente observada em vogais e consoantes no PB.

A seguir, na seção 2, é explicitada a teoria que embasa este artigo, descrevem-se também, a configuração do experimento e aspectos metodológicos. A seção 3 discute quantitativa e qualitativamente os resultados obtidos. Por último, a seção 4 apresenta a conclusão e aponta possibilidades para pesquisas futuras.

\section{Estudo de caso: formas de plural de nomes terminados em sibilantes}

Esta seção apresenta as teorias adotadas neste artigo. Além disso, expõem-se a configuração do experimento e a metodologia utilizada.

\subsection{Teorias fonológicas}

Teorias fonológicas tradicionais assumem que a representação lingüística é categórica. No entanto, trabalhos recentes desafiam essa visão na medida em 
que postulam que as representações lingüísticas incorporam informações redundantes as quais desempenham papel fundamental no processamento da linguagem. Dentro dessa perspectiva, propriedades estruturais são compreendidas como parte de um continuum com comportamento gradiente (BOD; HAY; JANNEDY, 2003, p.1). Teorias capazes de abarcar tais descobertas devem assumir múltiplos níveis de representação (PIERREHUMBERT, 2003; CRISTÓFAROSILVA; GOMES, 2004). Trabalhos experimentais em fonética podem fornecer evidências para a gradualidade inerente ao contínuo da fala, indicando assim a natureza gradual das representações fonéticas. Este trabalho pretende contribuir para pesquisas que seguem essa linha de pensamento ao avaliar se a perda de uma categoria fonológica (plural) deixa pistas no contínuo da fala.

Os modelos multirrepresentacionais que apóiam o presente trabalho são aFonologia de Uso (Bybee, 2001) e a Fonologia Probabilística (PIERREHUMBERT, 2001, 2003). Esses modelos assumem que palavras (e frases muito freqüentes) são as unidades de representação. Tais unidades são organizadas em uma rede de conexões que opera em vários níveis, como o semântico, morfológico, etc (GOLDLINGER, 1997; BYBEE, 2001). No caso das formas nominais, ambas as representações, singular e plural, são listadas no léxico. Um morfema utilizado para o plural, que tem função de expressar quantidade, é conectado a vários outros morfemas de plural caracterizando uma unidade relevante na rede. Formas de singular e plural também são relacionadas em nível semântico e assim, conectadas entre si.

Além dos modelos multirrepresentacionais mencionados acima, assumem-se os fundamentos teóricos da Fonologia Articulatória (BROWMAN; GOLDSTEIN, 1992). A Fonologia Articulatória sugere que os gestos articulados durante a produção da fala se sobrepõem e interagem entre si. Trabalhos experimentais devem, portanto, encontrar resultados que confirmem essa teoria. Este artigo adota ainda aspectos da teoria acústica da fala (STEVENS, 1998). Pretende-se mostrar que a perda da marca de plural está relacionada com o aumento da duração da vogal tônica e da sibilante final da forma nominal. Os resultados apresentados contribuem para o desenvolvimento de modelos multirrepresentacionais, para a avaliação da gradualidade fonética nas representações lingüísticas e, também, para trabalhos em fonética experimental. A próxima seção descreve o experimento que investiga a perda da marca de plural em palavras terminadas em sibilante no PB. 


\subsection{Configuração do Experimento}

O experimento descrito a seguir foi realizado na cidade Belo Horizonte, Minas Gerais, Brasil (www.pbh.gov.br) na Universidade Federal de Minas Gerais (www.ufmg.br). Belo Horizonte é a terceira maior cidade do Brasil, possuindo mais de dois milhões de habitantes. O experimento realizado buscou coletar dados de pessoas de diferentes sexos (4 mulheres e 4 homens) que foram divididos em 2 grupos (acima de 40 e abaixo de 25 anos). $O$ grau de escolaridade também foi considerado, agrupando-se os falantes em nível universitário/superior e escolaridade até a $8^{\mathrm{a}}$ série. A freqüência de ocorrência das palavras também foi considerada, sendo extraída do Banco do Português (http://lael.pucsp.br/corpora/index.htm). Tal corpus possui um total de 233 milhões de palavras. A frequiência de ocorrência das palavras utilizadas no experimento é apresentada mais adiante, na Tabela 2.

Para coletar dados específicos a respeito de formas nominais de plural (e da perda de marca de plural), construiu-se um experimento que foi realizado em três etapas: a) elicitação, b) leitura de lista de palavras e c) leitura em contexto (cf. www.projetoaspa.org/35lsrl para consultar o material do experimento). Na primeira etapa do experimento, algumas figuras foram apresentadas e os participantes foram orientados a descrevê-las de tal maneira que as formas singulares e formas de plural fossem pronunciadas. Na segunda etapa do experimento pediu-se aos participantes a leitura de um texto em voz alta. O texto continha todas as formas de singular e plural das palavras que constavam da tarefa de nomeação de figuras da primeira etapa. Vale destacar que a história apresentada no texto era bastante interessante e os participantes se mostraram curiosos para saber como ela se desenvolveria. Entende-se que esse fato contribuiu para que os participantes desviassem a atenção da real motivação do experimento. Finalmente, na terceira etapa do experimento, pediu-se aos participantes a leitura em voz alta de uma lista de palavras que continha todas as palavras das etapas anteriores, bem como algumas palavras distratoras. Um conjunto de 14 palavras, em suas formas de singular e plural, foi analisado no experimento. As palavras utilizadas no experimento são apresentadas na Tabela 2.

Sete palavras monossilábicas e sete palavras dissilábicas foram coletadas na realização do experimento. Amostras dessas palavras foram coletadas na forma singular e plural para todos os participantes em três etapas do experimento. A Tabela 2 apresenta a forma singular das palavras utilizadas no experimento. As formas de plural também foram investigadas. Note que todas as possibilidades 
de vogais tônicas do PB foram consideradas tanto para as palavras monossilábicas quanto para as dissilábicas: [i, e, $\varepsilon, a, i, o, 0, u]$. O experimento coletou e analisou 336 palavras no plural (14 palavras $\mathrm{x} 8$ informantes $\mathrm{x} 3$ etapas). As palavras em suas formas de singular e as palavras distratoras contam como dados extras. Portanto, conta-se com 336 palavras em forma de singular (14 palavras $\mathrm{x} 8$ informantes $\mathrm{x} 3$ etapas).

As três etapas do experimento foram gravadas em cabine acústica. Foram utilizados gravador digital e microfone unidirecional. Cada forma nominal a ser analisada foi editada e gravada em arquivo individual o qual foi posteriormente analisado com o auxílio do software PRAAT (www.praat.org). Usando as ferramentas do PRAAT, as palavras foram divididas em dois grupos. O primeiro grupo continha as palavras que possuíam a marca de plural (-is); já o segundo grupo não possuía tal marca de plural. Para caracterizar as palavras do primeiro grupo, buscou-se identificar a presença de uma vogal átona na última sílaba, a qual seria seguida de uma sibilante, i.e. [is], que corresponderia à marca do plural. ${ }^{7}$ Os casos em que a vogal átona na última sílaba não foi experimentalmente encontrada foram classificados como não possuindo marca de plural.

TABELA2

Palavras utilizadas no experimento e respectivas freqüências de ocorrência

\begin{tabular}{|c|c|c|c|c|}
\hline \multirow[b]{2}{*}{ Vogal } & \multicolumn{2}{|c|}{ Monossílabos } & \multicolumn{2}{|c|}{ Dissílabos } \\
\hline & Palavra & $\begin{array}{l}\text { Freqüência } \\
\text { de Ocorrência }\end{array}$ & Palavra & $\begin{array}{l}\text { Freqüência } \\
\text { de Ocorrência }\end{array}$ \\
\hline /i/ & $X(x i s)$ & 0 & Nariz & 144 \\
\hline le/ & vez & 78211 & Chinês & 3831 \\
\hline $\mid \varepsilon /$ & $d e z$ & 0 & Viés & 25 \\
\hline la/ & gás & 1989 & Rapaz & 3100 \\
\hline /o/ & $K o ̂ s$ & 0 & Arroz & 2 \\
\hline / / & voz & 4622 & Queiróz & 0 \\
\hline$/ \mathrm{u} /$ & luz & 3072 & Capuz & 103 \\
\hline
\end{tabular}

Essa classificação categórica, i.e., contêm ou não contêm a marca de plural, foi utilizada na análise quantitativa que buscou avaliar os casos em que a marca de plural estava presente (ou não) na forma plural. Para o grupo de palavras que continha a marca de plural, como em [' mezis], mediu-se a 
duração dos seguintes segmentos: vogal de acento primário, a sibilante seguinte, a vogal alta átona e a sibilante final. Para o grupo de palavras que não continha a marca de plural, mediu-se a duração dos seguintes segmentos: vogal de acento primário, a sibilitante seguinte a qual ocorre em posição final.

A hipótese deste artigo, a qual teve origem em observações auditivas, postula que a perda da marca de plural deixaria, de alguma maneira, vestígios no contínuo da fala. Mais especificamente, postula-se que, em palavras terminadas em (-s), que possuem marca de plural como (-is), observar-se-ia o aumento na duração da vogal tônica ou da fricativa (ou ambas) quando "aparentemente" perdia-se a marca de plural.

Note que todas as formas singulares de palavras na Tabela 2 possuem acento primário na vogal final, sendo tal vogal seguida por uma sibilante que ocorre no final da palavra. Assim, todas as palavras selecionadas para análise têm a forma singular terminada em (-s), e a forma plural deveria ser acrescida da seqüência segmental (-is): [' mes] mês e [' mezis] meses. As formas de plural deveriam apresentar uma vogal tônica seguida por uma sibilante que, por sua vez, é seguida por uma vogal alta postônica e por outra sibilante (já que a marca do plural é dada por (-is)). Portanto, tem-se uma sequiência segmental do tipo (vogal tônica + sibilante do final da palavra no singular + (-is)): mesiz. Nesse contexto, a vogal alta postônica que ocorre entre as fricativas sofre processo de lenição. Como consequiência da lenição da vogal, observa-se que os gestos das sibilantes adjacentes se sobrepõem. A sobreposição de gestos leva ao aumento da duração dos segmentos adjacentes, ou seja, a vogal tônica e as fricativas, sendo que as fricativas passam a ser contíguas (uma vez que a vogal sofreu lenição). O resultado é que as formas que sofreram lenição, i.e., as formas que são consideradas como tendo perdido a marca de plural, na verdade apresentam apenas uma sibilante após a vogal tônica e esta sibilante apresenta duração maior do que a duração média das sibilantes em fim de enunciado no PB. Argumentase que é a maior duração dos segmentos (vogal tônica e sibilante final) que caracteriza a forma nominal como sendo de plural em contraste com as formas singulares.

Com o objetivo de investigar essa hipótese, ou seja, o aumento da duração da vogal tônica e da sibilante final, mediu-se a duração de tais segmentos para cada palavra categorizada como tendo perdido a marca de plural. Os resultados são apresentados na seção seguinte. Inicialmente, são apresentados os resultados 
quantitativos que foram obtidos através do pacote de estatística do software Matlab. Em seguida, procede-se à análise experimental obtida através da análise do espectrograma das palavras gravadas e segmentadas através do software PRAAT.

\section{Resultados}

\subsection{Resultados quantitativos}

A lenição ocorreu em 30,1\% das formas de plural analisadas (101/336). Os resultados para as formas de plural as quais sofreram lenição são apresentados nas Tabelas 3 e 4 . Ressalta-se que a lenição ocorreu em formas com qualquer vogal tônica do PB e em todas as três etapas do experimento. Um resultado interessante foi o da maior ocorrência de lenição na etapa de leitura em contexto (cf. Tabela 4, coluna mais à direita). À primeira vista, a leitura em contexto pode ser entendida como um estilo mais formal no qual os participantes tenderiam a ser mais cuidadosos com suas pronúncias. Contudo, o texto utilizado nesta etapa era muito interessante e atraiu a atenção dos participantes de tal maneira que muitos disseram ter ficado curiosos para saber o final da história. O interesse demonstrado pelos participantes pelo teor do texto pode ter contribuído para um relaxamento maior durante a leitura o qual pode ter propiciado um estilo de leitura mais relaxado. Uma outra explicação para a maior taxa de lenição na etapa de leitura em contexto pode advir de fatores sintáticos envolvidos na perda da marca de plural (SCHERRE, 1998; NARO; SCHERRE, 2003). Sendo assim, espera-se que a marca de plural sofra lenição mais freqüentemente quando determinadas estruturas sintáticas estejam presentes, fato que ocorre na leitura em contexto. De qualquer forma, um resultado interessante apresentado na Tabela 4 é a ocorrência de lenição em todos os estilos de fala.

Pierrehumbert $(2001,2003)$ e Bybee $(2001,2003)$ fornecem evidências da relação entre a frequiência de ocorrência das palavras e a taxa de lenição. ${ }^{8}$ Essas autoras sugerem que mudanças foneticamente motivadas afetam as palavras mais freqüentes primeiro. Portanto, as palavras mais freqüentes deveriam sofrer lenição a uma taxa mais alta do que palavras menos frequientes quando há motivação fonética para o fenômeno. Isso decorre do fato de que em modelos multirrepresentacionais, como o Modelo de Exemplares (JOHNSON, 1997; 
PIERREHUMBERT, 2001), palavras de freqüência elevada e suas respectivas flexões têm representações mais robustas do que palavras raramente utilizadas.

Sugere-se que há motivação fonética para a perda de marca de plural em formas nominais terminadas em sibilantes. Tal motivação segue do fato de que uma vogal alta postônica com padrões duracionais muito baixos ocorre entre duas sibilantes postônicas (cf. MARUSSO, 2003 para valores duracionais). A posição postônica é prosodicamente fraca, sendo a vogal alta postônica articulada concomitantemente com as sibilantes, apresentando assim a lenição. Resultados relacionando freqüência de ocorrência e taxa de lenição são apresentados na Tabela 5. ${ }^{9}$ Uma análise geral dos dados apresentados na Tabela 5 indica que formas de plural de grande frequiência de ocorrência tendem a sofrer lenição a uma taxa mais alta do que formas de plural com menor freqüência de ocorrência. Mais adiante, o gráfico da Figura 1 indica a taxa de lenição para cada palavra individualmente. As palavras menos freqüentes situam-se mais à esquerda e as mais freqüentes mais à direita do gráfico.

TABELA 3

Distribuição da ocorrência de lenição de acordo com vogais e número de sílabas

\begin{tabular}{rcccc}
\hline \hline Vogal & Monossílabo & Dissílabo & \multicolumn{2}{c}{ Total } \\
\hline /i/ & 5 de 24 & 9 de 24 & 14 & $29.1 \%$ \\
/e/ & 8 de 24 & 9 de 24 & 17 & $35.4 \%$ \\
/E/ & 6 de 24 & 9 de 24 & 15 & $31.2 \%$ \\
/a/ & 7 de 24 & 8 de 24 & 15 & $31.2 \%$ \\
/o/ & 7 de 24 & 5 de 24 & 12 & $25.0 \%$ \\
/o/ & 9 de 24 & 6 de 24 & 15 & $31.2 \%$ \\
/u/ & 6 de 24 & 7 de 24 & 13 & $27.1 \%$ \\
Total & 48 de 101 & 53 de 101 & 101 & $30.1 \%$ \\
\hline \hline
\end{tabular}

TABELA 4

Distribuição da ocorrência de lenição de acordo com a natureza do experimento

\begin{tabular}{ccc}
\hline \hline Lendo uma lista de palavras & Elicitação & Lendo em contexto \\
\hline 18 de 112 & 34 de 112 & 49 de 112 \\
$15.2 \%$ & $30.4 \%$ & $43.8 \%$ \\
\hline \hline
\end{tabular}


TABELA 5

Porcentagem de lenição e freqüência de ocorrência

\begin{tabular}{cccrlcc}
\hline \hline & \multicolumn{3}{c}{ Monossílabo } & \multicolumn{3}{c}{ Dissílabo } \\
\hline Vogal & Palavra & $\begin{array}{c}\text { Taxa de } \\
\text { Lenição } \\
(\%)\end{array}$ & $\begin{array}{c}\text { Freqüência } \\
\text { de } \\
\text { Ocorrência }\end{array}$ & Palavra & $\begin{array}{c}\text { Taxa de } \\
\text { Lenição } \\
(\%)\end{array}$ & $\begin{array}{c}\text { Freqüência } \\
\text { de } \\
\text { Ocorrência }\end{array}$ \\
\hline /i/ & X(xis) & 20.8 & 0 & Nariz & 37.5 & 143 \\
le/ & vez & 33.3 & 81220 & Chinês & 37.5 & 3841 \\
/E/ & dez & 25.0 & 0 & Viés & 37.5 & 25 \\
/a/ & gás & 29.2 & 1979 & Rapaz & 33.3 & 3255 \\
/o/ & Kôs & 29.2 & 0 & Arroz & 20.8 & 2 \\
/o/ & voz & 37.5 & 4919 & Queiróz & 25.0 & 0 \\
/u/ & luz & 25.0 & 3076 & Capuz & 29.2 & 103 \\
\hline \hline
\end{tabular}

O gráfico da Figura 1 aponta uma tendência de palavras mais freqüentes possuírem maior taxa de lenição, contudo essa tendência não é muito clara. No entanto, se as palavras forem agrupadas de acordo com o logaritmo de suas respectivas frequiências, os resultados se tornam mais claros. Observe a Figura 2.

O gráfico da Figura 2 organiza as palavras em quatro grupos distintos de acordo com o logaritmo da freqüência de ocorrência. Nesse gráfico fica claro que palavras de menor frequiência de ocorrência tendem a ter menor taxa de lenição. Isto pode ser observado na Figura 2 através do maior índice de lenição quanto maior for a frequiência logarítmica. A idéia de agrupar as palavras em escala logarítmica da freqüência de ocorrência segue a análise de MendozaDenton, Hay \& Jannedy (2003) que propõem "there is a good evidence that humans often process frequent information in a logarithmic manner". 


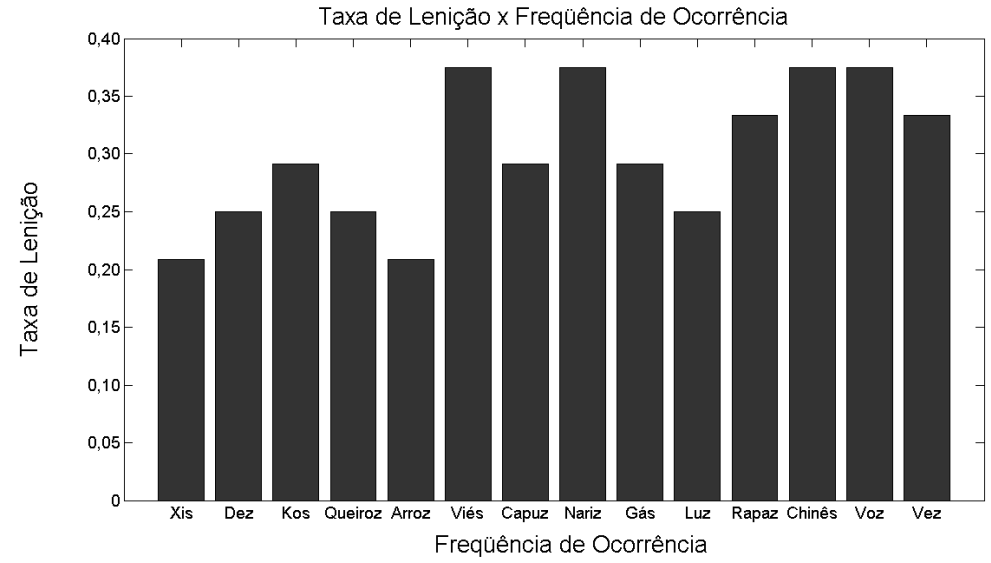

FIGURA 1 - Taxa de Lenição x Freqüência de Ocorrência

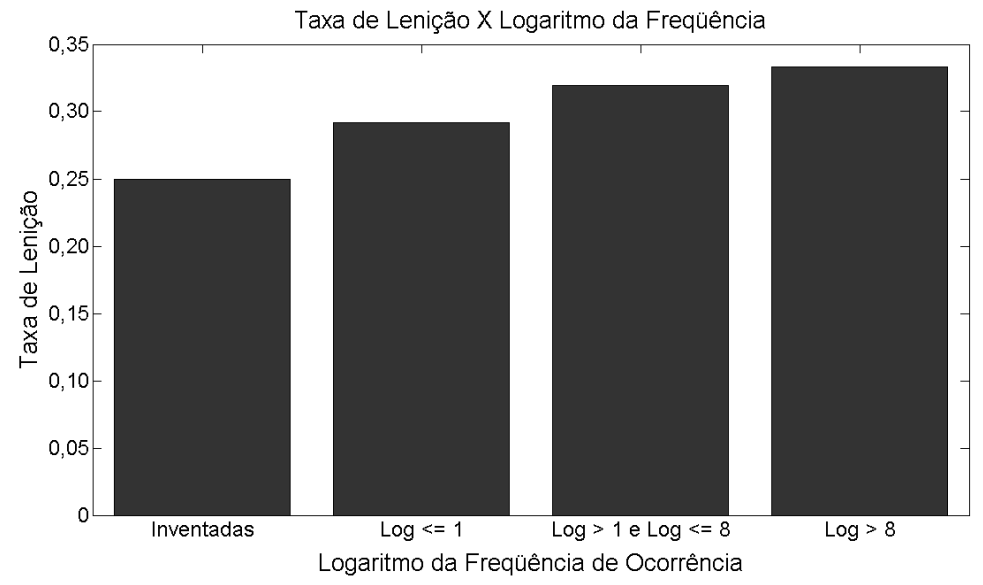

FIGURA 2 - Taxa de Lenição x Logaritmo da Frequiência. As 14 palavras foram dividias em 4 grupos de acordo com o logaritmo da freqüência de ocorrência.

A análise apresentada neste artigo dá suporte aos modelos multirrepresentacionais e, em particular, à Fonologia de Uso (BYBEE, 2000; 2001) e a Modelos de Exemplares (JOHNSON, 1997; PIERREHUMBERT, 2001). Tais modelos postulam que a frequiência de ocorrência tem papel crucial no modelamento das representações fonológicas. Os resultados estão em consonância com tais teorias, mostrando que palavras mais freqüentes tendem a ter maior taxa de 
lenição. Como conclusão parcial, pode-se destacar que a lenição das formas de plural ocorre em diferentes estilos de fala, para qualquer vogal tônica do PB, e, além disso, a freqüência de ocorrência tem papel relevante na determinação da taxa de lenição.

Conforme mencionado anteriormente, durante a análise quantitativa, as formas de plural foram agrupadas em dois grupos. As formas de plural do primeiro grupo possuíam a marca de plural (-is), já as formas de plural do segundo grupo, que sofreram lenição, continham apenas uma sibilante após a vogal tônica. Nota-se que os resultados obtidos são dificilmente representados por símbolos do alfabeto do IPA. Isso ocorre porque na análise do espectrograma das palavras analisadas encontram-se segmentos aparentemente iguais que diferem apenas quanto à duração. Sabe-se que a diferenciação de segmentos devido a sua duração não é uma característica comum do PB. Todavia, na análise apresentada neste artigo, encontraram-se formas no singular, como "mês" [ 'mes] com formas de plural com o sufixo (-is): "meses" [ ' mezis] e também encontraram-se formas de plural com lenição, i.e., a vogal átona postônica sofria lenição, não sendo manifestada. Os casos de lenição podem ser expressos pelos seguintes símbolos do IPA: [' mezs:s], ['mes: ] ou [ 'me: : ], , ou algumas combinações desses símbolos, mas há ambigüidade de interpretação fonética nesses casos. Tal ambigüidade observada no uso de símbolos IPA pode ser avaliada através de análises experimentais. A próxima seção discute este tópico.

\subsection{Análise experimental}

Esta seção apresenta o resultado das medidas de duração das vogais tônicas e das fricativas finais nas formas de plural que sofreram lenição (101/336). A duração da vogal tônica e da sibilante final foram medidas para todas as palavras que apresentaram perda de marca de plural. Também se mediu o tamanho das vogais tônicas e das fricativas finais das formas no singular correspondentes. Por exemplo, foram medidas a duração da vogal tônica e da sibilante final na forma singular "mês" [ ' mes] e também nas formas de plural em que não foi atestada a vogal do sufixo de plural (-is).

A hipótese a ser investigada nesta seção avalia se as vogais e as fricativas finais das formas no plural são significativamente maiores do que as formas no singular. A duração das vogais tônicas e das fricativas finais não são normalmente distribuídas e, sendo assim, optou-se pelo teste não-paramétrico Wilcoxon 
Ranksum. Dois testes de hipótese foram gerados, um para as vogais e outro para as fricativas. A hipótese nula sendo $\mathrm{H}_{0}$ : $\grave{\mathrm{i}}_{\text {plural }}=\grave{i}_{\text {singular }}$, i.e., a duração média do segmento no singular é igual a do segmento no plural, e a hipótese alternativa $\mathrm{H}_{1}$ : $\grave{i}_{\text {plural }}>\grave{i}_{\text {singular }}$ Os baixos p-valores para cada teste indicado na Tabela 6 levam à rejeição da hipótese nula. Em outras palavras, a duração média das vogais e fricativas aumenta quando a lenição ocorre.

Os resultados apresentados sugerem que a perda da marca de plural (-is) é na verdade foneticamente gradual, deixando vestígios através de uma vogal tônica alongada e de uma sibilante alongada a qual é também parcialmente vozeada. $\mathrm{O}$ fato discutido imediatamente anterior pode ser caracterizado como um fenômeno fonológico que é tipicamente conhecido como alongamento compensatório. Nesse caso específico, uma vogal é alongada quando um segmento adjacente se perde (TRASK, 1996, p. 81). Considerem-se os espectrogramas que seguem.

TABELA 6

Duração das vogais tônicas e das fricativas na ocorrência de lenição e p-valor para o teste de hipótese

\begin{tabular}{lcccccc}
\hline \hline & \multicolumn{2}{c}{ Duração do Singular } & & \multicolumn{2}{c}{ Duração do Plural } & \multirow{2}{*}{ P-valor } \\
\cline { 2 - 3 } & Média(s) & $\begin{array}{l}\text { Desvio } \\
\text { Padrão(s) }\end{array}$ & & Média(s) & $\begin{array}{l}\text { Desvio } \\
\text { Padrão(s) }\end{array}$ & \\
\hline Vogais & 0.177 & 0.077 & & 0.189 & 0.060 & 0,0184 \\
Fricativas & 0.206 & 0.101 & & 0.258 & 0.099 & $1,032 \times 10^{-4}$ \\
\hline \hline
\end{tabular}

$$
\mathrm{H}_{0}: \grave{i}_{\text {plural }}=\grave{i}_{\text {singular }} \text { versus } \mathrm{H}_{1}: \grave{1}_{\text {plural }}>\grave{i}_{\text {singular }}
$$



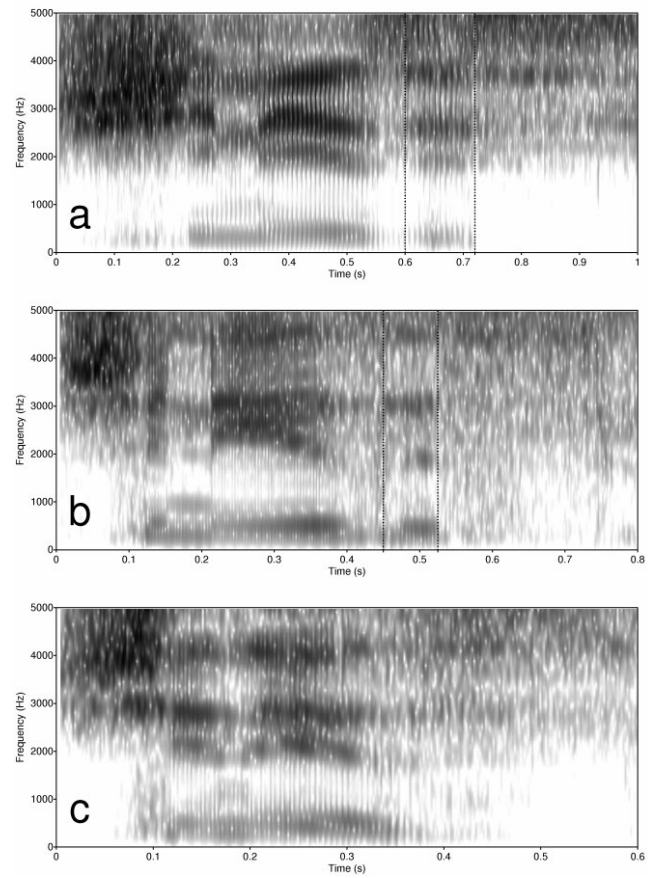

FIGURA 3 - Espectrograma da palavra "chineses": (a) ausência de lenição,

(b) lenição parcial, (c) lenição

Os espectrogramas da Figura 3 ilustram os resultados discutidos nesta seção. Todos os espectrogramas da Figura 3 correspondem à palavra "chineses" falada por três falantes distintos. Em (a), a vogal está presente e é destacada. Em (b), a vogal alta postônica quase desaparece, mas ainda pode ser visualizada entre as barras verticais. No entanto, em (c), a vogal alta postônica é apagada quando ocorre lenição e tal vogal não é pronunciada. Esses espectrogramas ilustram a gradiência envolvida no processo de perda da marca de plural.

Uma análise mais cuidadosa das figuras (3b) e (3c) encontra sinais de palatalização da fricativa final a qual pode estar relacionada à perda gradual da vogal alta postônica [i] (cf. ALBANO, 2001). Tais sinais de palatalização da fricativa final podem ser entendidos como mais uma evidência da gradualidade do processo de lenição aqui considerado. 


\section{Conclusão}

Este trabalho apresentou resultados que demonstram que o processo de lenição que afeta as formas de plural terminadas em sibilantes no PB ocorre em diferentes estilos de fala, com qualquer vogal na sílaba tônica, e que a freqüência de ocorrência está relacionada à taxa de lenição. Também se discutiu a variabilidade presente no sinal acústico das palavras que sofreram lenição. A perda da vogal alta postônica afeta segmentos adjacentes, ocasionando o alongamento da vogal tônica e da fricativa final. Os resultados aqui apresentados mostram que análises quantitativas e experimentais contribuem para o melhor entendimento da implementação gradual da variação fonológica na qual o detalhe fonético tem grande importância. Embora a forma singular e a forma plural que sofreu lenição apresentem seqüências segmentais similares como em [ ' mes] e [' me: : : ], o detalhe fonético revelado pela análise experimental mostra que, na verdade, as duas formas são sistematicamente diferentes. A diferença encontra-se justamente no alongamento tanto da vogal quanto da fricativa, embora o PB não faça distinção fonológica em termos duracionais. Experimentos futuros em percepção podem comprovar se o alongamento discutido neste trabalho oferece pistas relevantes para que os falantes identifiquem as formas de plural com sibilantes finais, as quais sofreram lenição.

Este artigo oferece evidências da implementação gradual de mudanças fonéticas em casos de variação sonora. Através de análises quantitativas e acústicas, foi demonstrado que a perda de uma categoria morfológica (o plural) deixa vestígios no contínuo da fala na forma de alongamento compensatório. Portanto, o presente trabalho contribui para uma pesquisa mais ampla sobre a perda de marca de plural no PB. Ao adotar a perspectiva da Fonologia de Uso (BYBEE, 2001) e da Fonologia Probabilística (PIERREHUMBERT, 2003), tentouse compreender um fenômeno que no futuro poderá servir de ponto de partida para teorias mais completas que integrem a fonologia, a morfologia e a sintaxe.

Finalmente, algo deve ser dito com relação às demais formas de plural do português brasileiro, as quais também sofrem perda da marca de plural (cf. Tabela 1). Nesse sentido, com relação às formas regulares de plural, "os meninos " > "os menino", não se conhecem trabalhos que tenham investigado a relação da sonoridade em tais casos. Contudo, pode-se sugerir que o alongamento da vogal tônica da forma nominal pode indicar que ocorre uma forma de plural. Essa hipótese poderá ser investigada em pesquisas futuras. 
Nos casos de metafonia, "uns r r[o]stos" > "uns r r[o]sto", Tomaz (2006) mostra que há grande variabilidade neste grupo de formas de plural. A autora oferece indícios da ocorrência de uma vogal com timbre vocálico intermediário entre uma vogal média-alta e média-baixa. Estudos pontuais sobre esse tópico devem ser empreendidos (cf. CAMPOS, 2005; ALVES, 1999).

Os casos de perda de marca de plural em formas nominais terminadas em lateral e em (-ão) foram analisados em Huback (2007). A autora mostra que a freqüência de ocorrência é crucial na organização dessas formas de plural. Correlatos sonoros não foram mencionados para esses grupos de plural.

Nos casos de formas nominais terminadas em róticos, "as flores" > "as flor", desconhecem-se trabalhos que investiguem o correlato sonoro da perda da marca de plural. Contudo, análises auditivas indicam que a vogal tônica pode ter duração maior do que a média das vogais tônicas em casos nos quais ocorre a perda da marca de plural.

Concluindo, pode-se dizer que as formas nominais terminadas em lateral e em (-ão) parecem não apresentar correlato sonoro quando ocorre a perda da marca de plural (HUBACK, 2007). Casos de metafonia indicam qualidade vocálica com timbre vocálico intermediário entre uma vogal média-alta e média-baixa (TOMAZ, 2006). Os casos do plural regular, formas nominais terminando em sibilante ou rótico podem ter como generalização o alongamento da vogal tônica quando há a perda da marca de plural. Este trabalho apresenta resultados referentes às formas nominais que terminam em sibilantes. Investigações futuras podem considerar os casos de formas nominais com plural regular e com plural em róticos com o objetivo de oferecer uma visão mais global do fenômeno discutido neste artigo.

\section{Notas}

${ }^{1}$ Os autores gostariam de agradecer os comentários que receberam sobre este artigo no III Congresso Internacional de Fonética e Fonologia (2006) e também no $35^{\text {th }}$ Linguistics Symposium of Romance Languages (2005). Os autores agradecem as sugestões e comentários dos pareceristas da Revista de Estudos da Linguagem, responsabilizando-se, contudo, pelos erros remanescentes. Thaïs Cristófaro Silva agradece o apoio do CNPq - processo 303397/2005-5. Leonardo Almeida agradece o apoio do $\mathrm{CNPq}$ - processo 507038/2004-5. 
${ }^{2}$ Para facilitar a leitura, daqui por diante, as marcas de plural serão destacadas por negrito e sublinhado.

${ }^{3}$ Faremos uso de "forma nominal" neste artigo como referência a um substantivo ou a um adjetivo.

${ }^{4}$ Análises sobre formas de plural de palavras terminadas em lateral em português (cf. Tabela 1, c) podem ser encontradas em Morales-Front \& Holt (1997) e Vigário (2003).

${ }^{5}$ Formas como "os mese", "os leõe", "as flore”, "os r[o]sto" ou "os anéi” não foram encontradas em nossos dados. Mencionamos esses dados atendendo solicitação de parecerista.

${ }^{6}$ Em Belo Horizonte, sibilantes pós-vocálicas são sistematicamente pronunciadas como alveolares: [s]. Esse padrão também se verifica em outras variedades do PB. Uma pronúncia alternativa para sibilantes pós-vocálicas, que é observada no Rio de Janeiro e outros estados do Nordeste, é a realização de uma consoante alveopalatal: [ $\left.\int\right]$. As sibilantes possuem vozeamento similar a outras consoantes quando em posição interna de palavra. Já em posição de final de palavra, sibilantes em coda no PB são tipicamentes desvozeadas, embora algumas variedades do Nordeste do país apresentem sibilantes alveolares vozeadas em posição pós-vocálica.

${ }^{7}$ A vogal postônica alta que ocorre na última sílaba (entre as sibilantes) é bastante curta (MARUSSO, 2003). A redução vocálica em posição postônica é uma característica marcante do BP, sendo refletida na menor duração dessa vogal se comparada às vogais em posição tônica e pretônica. Assim, a presença de formante que indica a presença de um elemento vocálico foi indício para caracterizar a palavra como apresentando marca de plural.

${ }^{8} \mathrm{~A}$ freqüência de ocorrência diz respeito a quantas vezes uma palavra ocorre em um determinado corpus.

${ }^{9}$ Ressaltamos que a frequiência de ocorrência na Tabela 5 refere-se às formas de plural. Observe que algumas das formas da Tabela 3 apresentam (zero) como freqüência de ocorrência, i.e., essas palavras não ocorrem. Elas se enquadram em dois grupos: a) a palavra não é tipicamente pluralizada (como o numeral "dez", a letra "X" ou o sobrenome "Queiróz") ou b) a palavra foi inventada (cf. "kôs"). 


\section{Referências Bibliográficas}

ALBANO, Eleonora C. O gesto e suas bordas: esboço de fonologia acústicoarticulatória do português brasileiro. Campinas: Mercado de Letras, 2001.

ALVES, M. As vogais médias em posição tônica nos nomes do português brasileiro. 1999. Dissertação (Mestrado) - Faculdade de Letras, Universidade Federal de Minas Gerais, Belo Horizonte, 1999.

BOD, R.; HAY, J.; JANNEDY, S. (Ed.). Probabilistic Linguistics. Cambridge Massachussets: MIT Press, 2003.

BROWMAN, C.; GOLDSTEIN, L. Articulatory Phonology. Phonetica 49, p.155180, 1992.

BYBEE, J. Mechanisms of Language Change as universals of language. To be translated in Spanish as Los Mecanismos del Cambio Como Universales Lingüísticos. To appear in MAIRAL, R.; GIL, J. (Ed.). Entorno a los universales lingüísticos. Cambridge: Cambridge University Press, 2003.

BYBEE, J. Word frequency and context of use in the lexical diffusion of phonetically conditioned sound change. Language Variation and Change, v. 14, p. 261-290, 2002.

BYBEE, J. Phonology and Language Use. Cambridge University Press, 2001.

BYBEE, J. The phonology of the lexicon: evidence from Lexical Diffusion. In: BARLOW, M.; KEMMER, S. (Ed.). Usage-based models of language. Stanford California: CSLI Publications, 2000. p. 65-85.

CAMPOS, S. Abertura vocálica em verbos irregulares da primeira conjugação do português: um caso de reestruturação fonotática por generalização fonológica. 2005. Dissertação (Mestrado) - Faculdade de Letras, Universidade Federal de Minas Gerais, Belo Horizonte, 2005.

CRISTÓFARO-SILVA, T. Fonética e Fonologia do português: roteiro de estudos e guia de exercícios. São Paulo: Contexto, 2002.

CRISTÓFARO-SILVA, T.; GOMES, C. Representações múltiplas e organização do componente lingüistico. Florianópolis: Fórum Lingüístico, 2004.

CRISTÓFARO-SILVA, T., GUIMARÃES, D.; HUBACK, A. P.; GOMES, C. The acquisition of irregular plurals in Brazilian Portuguese. Paper presented at the $\mathrm{X}$ International Congress for the Study of Child Language in Berlin, 2005.

CUNHA, C.; L. CINTRA, L. Nova gramática do português contemporâneo. Rio de Janeiro: Nova Fronteira, 1985. 
GOLDINGER, S. D. Words and voices: perception and production in an episodic lexicon. In: JOHNSON, K.; MULLENIX, J. (Ed.). Talker variability in speech processing. San Diego: Academic Press, 1997. p. 33-66.

GUY, G. Linguistic Variation in Brazilian Portuguese: Aspects of the phonology, syntax, and language history. University of Pennsylvania PhD dissertation. Published: Sydney: Sydney University, Department of Linguistics, 1981.

On the nature and origins of popular Brazilian Portuguese. In: Estudios Sobre Español de América y Lingüística Afroamericana. Bogotá: Instituto Caro y Cuervo, 1989. p. 227-245.

HUBACK, A. P. Efeito de freqüência nas Representações Mentais. 2007. Tese (Doutorado) - Faculdade de Letras, Universidade Federal de Minas Gerais, Belo Horizonte, 2007.

JOHNSON, K. Speech perception without speaker normalization: an exemplar model. In: JOHNSON, Keith; MULLENIX, John W. (Ed.). Talker variability in speech processing. San Diego: Academic Press, 1997. p. 145-165.

MARUSSO, A. Redução vocálica: estudo de caso no português brasileiro e no inglês britânico. 2003. Tese (Doutorado) - Faculdade de Letras, Universidade Federal de Minas Gerais, Belo Horizonte, 2003.

MENDOZA-DENTON, N.; HAY, J.; JANNEDY, S. Probabilistic Sociolinguistic: Beyond Variable Rules. In: BOD, R.; HAY, J.; JANNEDY, S. (Ed.). Probabilistic Linguistics. Cambridge Massachussets: MIT Press, 2003.

MORALES-FRONT, A.; HOLT, D.E. On the interplay of morphology, prosody and faithfulness in Portuguese pluralization. In: MARTINEZ-GIL; MORALESFRONT, A. (Ed.). Phonology and Morphology of the Major Iberian Languages. Washington D.D. Georgetown University Press, 1997. p. 393-437.

MOWREY, R.; W. PAGLIUCA. The reductive character of articulatory evolution. Rivista di Linguistica 7, p. 37-124, 1995.

NARO, A. J.; SCHERRE, M. Estabilidade e Mudança Lingüística em Tempo Real: A Concordância de Número. In: PAIVA, Maria da Conceição; DUARTE, Maria Eugênia Lamoglia (Ed.). Mudança Lingüística em Tempo Real. Rio de Janeiro, v. 1, p. 47-62, 2003.

PIERREHUMBERT, J. Probabilistic phonology: discrimination and robustness. In: BOD, R.; HAY, J.; JANNEDY, S. (Ed.). Probabilistic Linguistics. MIT Press, 2003. p. $177-228$. 
PIERREHUMBERT, J. Exemplar dynamics: Word frequency, lenition and contrast. In: BYBEE, J.; HOPPER, P. (Ed.). Frequency effects and the emergence of linguistic structure. Amsterdam: John Benjamins, 2001. p. 1-19.

QUEDNAU, L. R. A vocalização variável da lateral. Letras de Hoje, Porto Alegre, v. 29, n. 4, p. 143-151, 1994.

SCHERRE, M. Reanálise da Concordância Nominal em Português. 1998. Tese (Doutorado em Lingüística) - Universidade Federal do Rio de Janeiro, 1998.

STEVENS, K. Acoustic Phonetics. Cambridge. MA: MIT Press, 1998.

TOMAZ, K. Metafonia nominal no português. 2006. Dissertação (Mestrado) Faculdade de Letras, Universidade Federal de Minas Gerais, Belo Horizonte, 2006.

TRASK, R. L. A Dictionary of Phonetics and Phonology. London \& New York: Routledge, 1996.

VIGÁRIO, M. The Prosodic Word in European Portuguese. Interface Exploration Series, 6. Berlin. New York. Mouton de Gryter, 2003.

ZSIGA, E. C. An acoustic and electropalatographic study of lexical and postlexical palatalization. In American English. In: CONNELL, B.; ARVANITI, A. (Ed.). Phonology and Phonetic Evidence: Papers in Laboratory Phonology IV. Cambridge: Cambridge University Press, 1995. p. 282-302. (also published in Haskins Laboratories Status Report on Speech Research. SR 117/118. p. 1-14). 